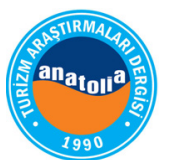

\section{Şiddet, Suç ve Na-Hoş Zaman ilişkisi}

\section{GiRiş}

Ülkemizde rekreasyon ile ilgili yazılan makaleler incelendiğinde, büyük bir çoğunluğunda öncelikle bu ifadenin tanımlanmasının yapıldığı gözlemlenmektedir. Çoğu zaman bu alanda çalışan meslektaşlarım ve şahsım bu tekrarları eleştirmektedir. Eleştirinin temelinde hep benzer tanımların yapılması ve sanki makale yazmak için kelime sayısının artırılması veya belirli bir alanın doldurulması adına, bu kavramın temcit pilavı şeklinde ele alınması yatmaktadır. Öte yandan, rekreasyonun ve onun oluşabilmesi için temel parça olan boş zamanın (leisure) etimolojik açıdan incelemesi ve farklı kültürlerdeki anlamı yeterince değerlendirilmemekte, felsefi derinliği genelde göz ardı edilmektedir. Bu nedenle bu çalışmada şiddet, suç ile rekreasyon-boş zamanı ilişkilendirmeden önce bazı tanımlar öncelikle ele alınacak, ardından tanımlamalar içindeki anlamlar çerçevesinde, şiddet, suç ve na-hoş zaman ilişkisi değerlendirilecektir.

\section{REKREASYON VE HOŞ ZAMAN}

Rekreasyon kelimesi dil bilim açısından İngilizce yaratmak, oluşturmak anlamına gelen "create" fiilinin önüne; yeniden, tekrar anlamına gelen "re" ön ekinin gelmesiyle oluşmuştur. İngilizce konuşan coğrafyada iş-çalışma hayatı ve diğer etmenler tarafından yıpranan, yorulan bireylerin tekrar enerji depolamaları ve yeniden canlanmaları anlamında kullanılan bir ifadedir (Axelsen 2009). Bununla birlikte rekreasyon faaliyetlerini gerçekleştirebilmek için yine İngilizce konuşan coğrafyada "leisure" denilen, Türkçe karşılığıyla boş zamana gereksinim vardır. Öte yandan keli-

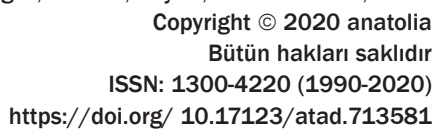

\section{Özkan TÜTÜNCÜ}

Dokuz Eylül Üniversitesi

Spor Bilimleri Fakültesi

menin farklı dillerdeki anlamı ve ifade edilişleri değişiklik göstermektedir. Latince "Licere-licet" kelimesinden türeyen leisure, eski Fransızca'da loisir-leisur olarak ele alınmaktadır (Wiktionary 2020). Latince "licere" özgür ve izin verilen anlamında kullanılırken, eski Fransızca'da anlamı dinlenme, izin verilen, hür-serbest zaman olarak ele alınmaktadır. Latince kökenleri aynı olmakla birlikte İngilizce ve Fransızca'da anlamları arasında bir karmaşa olduğu belirtilebilir (Torkildsen 1999).

Boş zaman iş, uyku ve diğer temel ihtiyaçlara ayrılan süreden, bireye arta kalan zaman olarak değerlendirilebilir. Temel ihtiyaçlar arasında yemek pişirme, alışveriş, ev işleri, çocuk bakımı ve hijyen; iş ile ilgili süreçlerde ise işin kendisi, işe gidiş-geliş ve seyahat süreleri ele alınmaktadır (Baud-Bovy ve Lawson 2002). Bireyin kendi takdirine göre istediği şekilde kullanılabildiği zaman, genel olarak boş zaman şeklinde ifade edilebilir.

Diğer dillerde "leisure" İngilizce'deki anlamından farklı ifade edilebildiği gibi Türkçe'de de bire bir tercümede anlam uyuşmazlıklarına neden olabilmektedir. Türkçe'de boş zaman kelimesi, aylaklık ile eş değer bir şekilde değerlendirilebilmektedir. Oysaki "boş zamanda-leisure" anlatılmak istenen, boş boş yapılan işlerin zamanı değil, bireye özgür iradesiyle yaptığı için keyif veren "hoş zaman" dır. Boş zaman dendiğinde ortaya çıkan yanlış anlamaları önleyebilmek için zaman zaman "serbest zaman" ifadesi kullanılmaktadır. Boş zaman yerine serbest zamanın kullanılması durumunda, kendi öğrencilerim dahi uyararak kesin bir tutum ile "boş zaman” olarak 
cümlenin değiştirilmesi gerektiğini vurgulamaktadır. Serbest zaman ve boş zamanın anlamı arasında farklılık bulunduğu bir gerçektir. Çalıştığınız işte verilen bir mola, serbest zaman olarak nitelendirilebilir ve bunun boş zamandan farklı bir anlama büründügü bir gerçektir. Öte yandan, farklı dillerdeki anlamlarında dahi karışıklıklar bulunan bu ifadeyi, çok keskin sınırlar ile tanımlamaya çalışmak yanlış sonuçlar doğurabilir. Di$\breve{g}$ er bir ifade ile serbest zamanda yapilan faaliyetler, rekreatif faaliyet etkisi yaratmazlar mi veya bırakın serbest ve boş zamanı, kendi tercihiniz olmasa bile zorunlu olarak geçirmeniz gereken bir zamanda, rekreatif faaliyetler yapılamaz mı ve temel olarak rekreasyon-boş zamanı kesin s1nırlar ile belirlemek mümkün müdür sorularının olası yanıtları bu makalede tartışılmaya çalışılacaktır.

\section{REKREASYON VE SAĞLIK}

Rekreatif etkinlikler, bireyin yaşamındaki birçok sıkıntıdan kurtulmasını ve bireyin kendisini geliştirmesini sağlayarak, bireylerin psikolojilerine, ilişkilerine ve sosyo-kültürel uyumlarına olumlu yönde etkilemektedir (Karaküçük 1997; Iwasaki 2007; Patry ve diğ. 2007; Şener ve diğ. 2007; Axelsen 2009). Genel anlamda rekreasyon faaliyetlerini, insanların boş zamanların$\mathrm{da}$, bazen eğlence ve tatmin (hedonic) bazen ise erdemsel (eudaimonic) amaçlar ile yaptıkları ve gönüllü olarak katıldıkları faaliyetler biçiminde tanımlanabilir. Diğer bir ifade ile genel olarak bireyin yaşam kalitesini artırmak için yaptı̆̆ $\mathrm{fa}$ aliyetler rekreasyonun içeriğini oluşturmaktadır (Tütüncü vd. 2011). Rekreasyonun Türkçe karş1lığ 1 "dinlence" olarak ele alınabilir. Turizm veya spor faaliyetleri (profesyonelce yapılmayan), bireyin boş zamanında gerçekleştirdiği rekreatif faaliyetler olarak değerlendirilebilir.

İnsanların uzun ve sağlıklı yaşama istekleri, onları hem fiziksel hem de mental olarak rahatlamalarına firsat tanıyan rekreasyon faaliyetlerine yöneltmektedir (Sağcan 1986). Bu kapsamda bireyler çalışma hayatlarının en iyi ihtimalle üçte birini rekreasyon faaliyetlerinde geçirmektedir. Çünkü günün ortalama sekiz saati çalışmak, ortalama 8-10 saati temel ihtiyaçlar (uyku, temizlik, hijen, yemek vb.) için geçmekte geri kalan kısmı boş zaman olarak değerlendirilebilmektedir. Boş zaman ve rekreasyon faaliyetleri sağlıklı ve/veya engelli olan her yaşta ve beceri seviyesinde tüm bireyleri kapsamakta ve onların mutlu-kaliteli yaşama eğilimlerine bağlı olarak gelişmektedir. Sağlık açısından rekreasyon temel olarak iki k1sımda değerlendirilmektedir. Bunlardan ilki koruyucu sağlık hizmetleri kapsamında sağlıklı bireylere, ikincisi ise iyileştirme ve esenlik (rehabilitasyon) hizmetleri kapsamında engelli ve sağlık sorunları olan kişilere (zaman zaman dezavantajlı gruplara) verilen rekreasyon hizmetleridir (Tütüncü 2008). Dünyada sağlıklı bireylere verilen rekreasyon hizmetleri "Rekreasyon" kapsamında; engelli, sağlık sorunu olan ve/veya dezavantajlı gruplarda yer alan bireylere verilen rekreasyon hizmetleri "Terapötik Rekreasyon" kapsaminda değerlendirilmektedir (Austin 2004).

İnsanın aile, okul veya iş hayatındaki sorunları sinir sistemini bozabilmekte, yorulma ve dayanma gücünün azalmasına neden olabilmektedir. Teknolojinin ve hayatın tekdüzeliğinin getirdiği stres, kişiye fizyolojik ve psikolojik anlamda büyük rahatsızlıklar oluşturabilmektedir. Daha çok grup ve ekip olarak gerçekleştirilen rekreatif faaliyetler, insanın sosyal ilişkiler kurmasında ve geliştirmesinde büyük rol oynamaktadır. Bu etkinliklere bağlı olarak, yeni arkadaşlıkların oluşması, grup içinde yer edinme ve diğer grup üyelerini tanıyabilme gibi çabalar, kişinin sosyal yaşantısını etkileyerek olgunlaşmasını ve toplum hayatına alışmasını sağlamakta (Karaküçük 1997) ve hayatı anlamlandırmaktadır.

İnsanoğlunun yaşam sürecinde doğaya ve rekreasyon faaliyetlerine olan istemi farklı dönemlerde değişik nitelik ve boyutlarda olduğundan, yaşam alanlarında bu istemi karşılayabilecek birtakım olanakların oluşturulması ve geniş bir yelpaze içinde sunulması, yaşam kalitesi açısından ayrı bir önem taşımaktadır (Tütüncü 1997). Genellikle az gelişmiş veya gelişmekte olan ülkelerde işlevsel olmayan yaşam alanları, birtakım sorunların doğmasına neden olmaktadır. Özellikle fiziksel bakımdan insanın en aktif olduğu gençlik yıllarında rekreatif faaliyetlerin yapılaca$\breve{g}$ ı alanların ve olanakların olmaması, bu fiziksel 
enerjinin başka bir şekilde olumsuz olarak ortaya çıkmasına da neden olabilmektedir. Hatta rekreatif olanakların yetersiz olmasının yaratacağ olumsuz birikimler, geleceğin bireylerine çeşitli biçimlerde ortaya çıkabilecek olan nevrozların da tohumlarını atmaktadır (Usal 1981).

\section{REKREASYON, SUÇ VE ŞIDDET}

Türk Dil Derneğine göre suç; yasalara, törelere ve ahlaki değerlere aykırı davranış, şiddet ise sindirmek için yaratılan olay veya eylem-kaba kuvvet olarak tanımlanmaktadır. Dünya'da her gün ortalama 4200 kişi, yılda 1,6 milyon kişi şiddetten (Butchard vd. 2008), 2,1 milyon kişi ise cinayetten ölmektedir (UNODC 2020). Ayrıca 14-44 yaş arası ölümlerin en önemli ana sebebi şiddet olmaktadır (DSÖ 2012). Birleşmiş Milletler'e (2020) göre Dünya'daki her üç kadından biri fiziksel veya cinsel şiddete maruz kalmakta, bazı ülkelerde bu durum \% 70'lere ulaşmaktadır. Dünya Bankası (1999) verilerine göre Dünya'daki halkın yarısının geliri günde iki doların altında, 1,2 milyar kişinin ise geliri bir doların altındadır. Oxfoam'ın raporuna göre Dünya üzerindeki 26 ailenin toplam geliri (1,4 trilyon ABD Doları), 3,8 milyar insanın toplam gelirinden daha fazladır (Quackenbush 2019). Gelişmekte olan ülkelerin iki trilyon dolar borcu bulunmakta ve bu ülkelerde doğan her insanın doğrudan 400 dolar borcu bulunmaktadır. Dünya'da 880 milyon kişi temel sağlık hizmetlerinden yoksun yaşamakta, 1,3 milyar kişi temiz içme suyuna ulaşamamakta, 872 milyon kişi okuma yazma bilmemektedir (Carnegie Council 2001).

Temel ihtiyaçlarını karşılamaktan yoksun kesimlerin, bu ihtiyaçlarını rekreasyon faaliyetinden önce gerçekleştirme istekleri doğal karşılanabilir. Ancak temel ihtiyaçlarını karşılayacak iş olanaklarını bulamamaları, bireyleri yaşamsal giderlerini karşılamak için yasal olmayan başka faaliyetlere itebilir. Yapılan araştırmalar kişisel gelirlerde $\% 10$ 'luk bir artışın suç oranında \%1,9 -2,5 azalmaya; işsizlikte \%10'luk bir azalmanın suç oranında \%2,2-2,3 azalmaya; genç erkek nüfusa artı $\% 10$ istihdam yaratılmasının, suç oranında \%2,74,1 azalmasına; herhangi bir bölgede işsizliğin \% 10 artmasının, bireye (mülke değil) yönelik suç oranlarında \% 6,14-6,25 artmasına neden olduğunu ortaya koymaktadır (Brosnan 2019). Bu eşitsizlikler akabinde istenilmeyen olayların çarpan etkisiyle artmasina neden olabilmektedir. Buna bağlı olarak yargı süreçleri, cezai yaptırımları beraberinde getirmektedir. Bu gibi durumlarda toplumların cezai yaptırımları ile karşılaşan kesimler için rekreasyon faaliyetleri ancak cezaevinde yapılabilecek bazı kısıtlı faaliyetlerle sınırlı kalabilmektedir.

Bugüne kadar yapılan çalışmalar, rekreasyonun bu faaliyete katılan bireyler üzerindeki olumlu etkilerini daha fazlasıyla incelemektedir. Bu çalışmalar aktif rekreatif faaliyetlerin, şiddet ve suç ile negatif yönde bir ilişkisinin olduğunu göstermektedir. Kaliforniya eyaletinde yapılan çalışmalar bireylerin ilk suç işledikleri yaşların genel olarak (bir çan eğrisi şeklinde) 13 ile 20 yaşlarında yoğunlaştığını (en yoğun 17 yaş) göstermekte (CDYA 2002) ve suç eğiliminin uzun süreler televizyon izleyen gençlerde daha yaygın olduğunu ortaya koymaktadır (Kolata 2002). Televizyonlardaki şiddet eğilimli yayınların, bunda etkisinin olduğu belirtilmekte (Jones Barclay ve Mawby 2012) ve hatta bazı yöneticiler okul eğitiminden sonraki saatlerde, aktif rekreasyon faaliyetlerine katılımın suç işleme oranını azaltacağ lanmaktadır (Schwarzenegger, Chrisman ve Coleman 2005). İngiltere'de 2012-2015 yılların kapsayan bir araştırma, spor faaliyetlerine katılımın \%10 düzeyinde artmasının, bireye yönelik suçların \%1,30-1,56; mülke yönelik suçların \% 0,640,73 azalmasına yardımcı olduğunu göstermiştir (Brosnan 2019). Bu etki belki düşük gibi gelebilir, ancak etkilerin farklı kültürlerde farklı olabileceği düşünülebilir. Carusso'nun (2011) İtalya'nın 20 bölgesinde yaptığ çalışma spor faaliyetlerine katılımın, suç oranlarında İngiltere'den daha fazla bir azalmaya neden olduğunu göstermiştir.

Rekreasyon bireylerin boş zamanlarda yaptıkları iş dışı hoş faaliyetleri kapsamakla birlikte, bireylerin boş zamanlarında gönüllü olarak çalıştığ 1 ve hatta kendi hayatını kazanmak zorunda olduğu işi ile ilgili faaliyetleri de içerebilmektedir. Kişinin yaşam kalitesi ve mutluluğunda, hedonist eğilimler kadar erdemsel faaliyetlerin de etkisi 
bulunmaktadır. Ayrıca iş hayatı (çalışma zamanı) ile rekreasyon (boş zaman) arasındaki ilişki çok yakın olup, kesin sınırlar ile çizilmiş te değildir. Filedelfiya kentinde polislerin gönüllü olarak halkın boş zamanlarında bitki yetiştirmesi için belediyelerce tahsis edilen alanları temizlemesinden ve kullanilacak hale getirmesinden sonra, kentteki suç oranının \%40 oranında azaldığı tespit edilmiştir (TPL 1997). Bununla birlikte suç oranının azalmasını sadece bu tip bir faaliyete bağlamak yanlış olabilir. Bu eyalette o dönemde yapılan diğer uygulamaların da ele alınmasında fayda bulunmaktadır. Öte yandan ABD'de yapılan diğer araştırmalarda rekreasyon alanların az olduğu bölgelerde, suç oranın arttığı saptanmıştır (Williamson 2000). Finiks eyaletinde yaz aylarında rekreasyon ve spor alanlarının gece saat ikiye kadar açık ve aktif tutulmasından sonra, gençlerin işledikleri suçlarda \%55 oranında bir azalma olduğu polisçe belirlenmiştir (TPL 2004). Virginya, Norfolk şehrinde polis, sosyal hizmetler bürosu ve halkın oluşturduğu spor liglerinden sonra, suç oranın \%29 oranın bir düşüş ile şehir çapında şiddet olaylarında bir azalma tespit edilmiştir (Mendel 2000). Avusturalya'da ise halkın aktif olarak katıldığı spor festivalleri ve faaliyetleri dönemlerinde şiddet olaylarına bir yavaşlama olduğu saptanmıştır (Cameron ve $\mathrm{MacDu}$ gall 2000).

Rekreasyon faaliyetlerinin genel olarak bireylerin suç ve şiddet eğilimlerini yavaşlattığına yönelik çalışmaların yanında, rekreatif faaliyetlerde meydana gelen suç ve şiddet olayları da araştırmacılar tarafından incelenmektedir. Bireylerin boş zamanlarında seyirci olarak katıldıkları bir spor müsabakasında ortaya çıkan holiganizm bu kapsamda ele alınabilir. Ayrıca rekreatif yoğunlaşmanın olduğu yerlerde suç oranlarının artı$\breve{g} 1$ bilinmektedir (Jones, Barclay, Mawby 2012). Turistik bölgelerdeki suç ve şiddet olaylarının artması, buna örnek olarak verilebilir. Bu bölgelerdeki suç ve şiddet olaylarının artmasında farklı faktörler rol oynayabilir. Gerçekleştirilen turizmin türü, gelen turistin ve halkın gelir seviyesi planlı (terör) ve fırsatçı (bireysel) suçları etkilemektedir (Braas 2015). Turizm suçlular için turistlere karşı işlenen suçlardan elde edilen ka- zancın yüksek, risklerin düşük olduğu koşullar yaratabilmektedir (Brunt ve Humbly 1999). Suça maruz kalan sadece rekreatif etkinliğe katılan turistler değil, bu hizmeti sunan veya orada yaşayan yerel halk ta olabilmektedir. Etkileri ise farklı şekillerde ortaya çıkabilmektedir.

İnsanlık tarihinde yaşanan korkunç bazı olaylar, rekreatif açıdan bireylerin ilgisini çekmektedir. Karanlık turizm adıyla gelişen bir olgu olarak, insanların soykırımların yapıldığı bölgeleri ziyaret etmesi bu kapsamda değerlendirilebilir. Bir Anzak'ın veya bir Türk'ün Çanakkale savaşlarının geçtiği ve ecdadının aslında acı çektiği alanları gezmesi buna iyi bir örnektir. Savaşlar, şiddet ve işlenen suçlar, değişik açılardan insanların ilgisini çekmektedir.

Yasal rekreatif faaliyetlerinin gerçekleştirilmesinde ortaya çıkan şiddet ve suçun yanında, bireylerin boş zamanlarında yasal olmayan na-hoş faaliyetler gerçekleştirerek şiddet ve suça karışmaları da incelenmesi gereken ayrı bir durumdur. Sapkın boş zaman (deviant leisure) faaliyetleri olarak sokakta gerçekleştirilen araba yarışları, uyuşturucu kullanımı, çocuk pornosu, hayvanların birbirine zarar verecek şekilde dövüştürülmesi, satanizm veya vandalizm bu kapsamda değerlendirilebilir (Williams ve Gordon 2006). Bazen de bireyler katıldıkları normal bir hoş zaman faaliyetinin içinde, kullandıkları yasal keyif verici maddelerin (alkol vb.) etkisi ile daha sonra pişman olabilecekleri na-hoş faaliyetler gerçekleştirmektedirler. Örneğin herhangi bir eğlence mekânında tüketilen alkole bağlı olarak çıkan kavga, alkollü taşıt kullanımına bağlı olarak yapilan kazalar veya benzerleri bu kapsamda değerlendirilebilir.

Boş zamanı hoş ve na-hoş zaman olarak değerlendirmek mümkündür. Bir boş ve hoş zaman faaliyeti olan turizmin olumlu etkileri kadar, olumsuz etkilerinin olduğu unutulmamalıdır. Turizm faaliyeti çekim gücü yaratmakta ve buna bağlı turistik destinasyonlarda suç oranları artabilmektedir. Yine bir boş zaman faaliyeti olarak spor müsabakalarını izleyen seyircilerin ortaya koyduğu holiganizm, bireylerin na-hoş zaman faaliyeti olarak neler yapabileceklerinin olumsuz göstergeleridir. Diğer bir ifade ile na-hoş zaman- 
larda gerçekleştirilen bazı rekreatif faaliyetlerin hem bireyler hem de toplumlar için olumlu sonuçlar doğurmadığ 1 bir gerçektir. Bu nedenle boş zaman faaliyetlerinin sadece olumlu etkilerinden bahsetmek ve olumsuz yönlerine değinmemek, yanlış sonuçlara neden olabilir. İster hoş bir zaman ister na-hoş bir zamanda bireyin kendi özgürlüğünü diğerinin özgürlügüunü kısıtlayacak şekilde kullanması, bir canlıya veya mülke zarar vermesi demokratik bir ülkede yasalar çerçevesinde cezalandırılmaktadır. Buna bağlı olarak hem mağdurların hem de suçluların durumları, na-hoş zamanlar için ayrı bir tartışma alanı yaratmaktadir.

\section{TARTIŞMA VE SONUÇ}

Boş zamanının birçok tanımı yapılmıştır ve yapılacaktır. Önceleri boş zaman iş-çalışma zamanının tamamen zıttı olarak değerlendirilirken, günümüzde boş zaman ve iş zamanı birbiriyle yakın ilişkili ve devam eden bir süreci açıklamaktadır (Torkildsen 1999). Çalışılan işte ortaya konulan çaba hem iş hayatında hem de boş zaman faaliyetlerinde söz konusudur (Meeras 2010). Jenkins ve Pigram (2006) boş zaman kavramının, emek ya da işe duyulan zorunluluk antitezinden daha fazlasını açıkladığını ifade etmektedir. İşsiz bireylerin boş zamanı vardır ancak bu onların bilinçli seçimleri değildir ve bu zamanın tamamının rekreatif anlamda boş zaman olarak değerlendirilmesi mümkün gözükmemektedir. Dinlence faaliyetlerini gerçekleştirebilmek için öncelikle bireylerin Maslow'un belirttiği birincil yaşamsal ihtiyaçları karşılayabilecek, ekonomik güce sahip olması gerekmektedir. Bazı rekreatif faaliyetleri gerçekleştirebilmek için yeterli bütçeye, dolayısıyla işe ve çalışma zamanına gereksinim bulunmaktadır. İnsanca yaşamak için gerekli olan geliri elde edemeyen bireylerin, boş zamanlarında na-hoş faaliyetlere, şiddet ve suça yönelmeleri mümkündür.

Boş zamanı tanımlamakta diğer bir zorluk ta bu zamanı seçme özgürlügüüüzden kaynaklanmaktadır. Tanıma göre kişinin bilinçli, gönüllü ve hür bir şekilde zamanını değerlendirmesi hedeflenmektedir. Acaba sığınma evindeki mağdur bir kadının ve/veya onu mağdur eden cezaevindeki bir erkeğin bulunduğu yerdeki durumu için boş zamandan bahsetmek mümkün müdür sorusu, rekreasyonun klasik sinırlı tanımının bu gibi durumlar için yeterli olmadığını ortaya çıkarmaktadır. Serbest zaman veya boş zamanın sınırlarını çizmek, çok keskin ve kesin şekilde tanımlamalar yapmak kolay değildir. Boş zamanın anlamı, var olan koşullara bağlı olarak, kişiden kişiye değişkenlik gösterebilir. Önemli olan zamanın tan1mindan ziyade, onun koşullar dahilinde nasıl değerlendirildiği ile ilgilidir. Bir mahkûm için cezaevindeki veya sığınma evindeki bir mağdur anne için zaman, o an itibarıyla tercih ettiği zaman değildir veya diğer bir ifade ile gönüllü olarak orada bulunmuyordur. Bununla birlikte bu şartlar altında dahi sı̆̆ınma evinde veya cezaevinde verilen bir meslek edindirme kursuna katılması, mahkumun cezaevi bahçesinde volta atması veya koğuşunda kitap okuması, mağdur annenin kızıyla sığınma evinde güzel bir sohbet etmesi, na-hoş bir zamanda yapılan bir hoş zaman aktivitesi olarak değerlendirilebilir. Bu nedenledir ki rehabilitasyon süreçlerinde rekreasyon terapistlerine gereksinim duyulmaktadır. Ayrıca bir cezaevinin veya sı̆̆ınma evinin sınırları içinde lojmanda yaşayan ve hayatının büyük bir çoğunluğu bu mekanlarda geçiren bir sı̆̆ınma evi veya cezaevi görevlisi için boş-serbest zaman ayrımını yapmak o kadar da kolay değildir. Bununla birlikte elbette burada yaşan ve çalışan kişilerin hem çalışma süreçleri içinde hem de işten arta kalan zamanlarında, boş ve serbest zaman iç içe geçmiş olsa da rekreatif faaliyetlerde bulunduklarını söylemek mümkündür.

Yapılan birçok çalışma rekreasyon alanlarının ve bu alanlarda yapılan aktif rekreasyon faaliyetlerinin insanların streslerini azalttığını, depresyona girmelerini önlediğini, suç oranlarını ve şiddetini azalttığını göstermektedir. Öte yandan hoş ve na-hoş zamanların isteyerek veya istemeden olumsuz etkiler yarattığını gösteren çalışmalar da bulunmaktadır. İnsanın şiddete olan eğilimi ve suç işleme yönelimi, çok boyutlu değişkenler ile değerlendirilmelidir. Rekreasyon alanlarının ve olanaklarının geliştirilmesinin, tek başına şiddet ve suç eğilimi azaltabileceğini belirtmek yanlış olabilir. Bireyin suç ve şiddete yönelmesinde; 
toplumun, bireyin kişisel yapısının, gelirinin ve diğer birçok faktörün birlikte etkisinin olduğu belirtmek daha doğru olabilir. Suç işlemiş (suçlu) veya işlememiş̧ (mağdur) her insanın kişiliğinin olumlu yönde gelişmesinde, rekreasyon faaliyetlerinin rolü büyüktür. Dezavantajlı grupların veya bireyin yaşam kalitesini artırmaya yönelik yapılan rekreasyon alanlarının ve sağlanan rekreatif olanakların, bireyin sağlıklı kalmasında ve rehabilitasyonunda rolü büyüktür. Suç ve şiddetten uzaklaşabilmek amacıyla insanlara gönlünce yaşayabilecekleri ve özgürlüklerini tadabilecekleri yeterli alanların sunulması ve yaşayabilecek geliri elde edebilecekleri iş olanakları ile boş zamanın yaratılması, her devletin öncelikli amacı olmalıdır.

Not: Covid-19 nedeniyle ilan edilen pandemiyi en az zararla atlatabilmek için sosyal izolasyona gerek duyulmaktadir. Var olan durum her bireyi doğal olarak kaygiya sürükleyebilmektedir. $\mathrm{Bu}$ dönemde ev içinde yapacağımız bazı rekreatif etkinlikler (ailemizle daha çok zaman geçirmek, okuyamadığımız kitapları ve makaleleri okumak vb.), süreci daha rahat atlatmamıza yardımcı olacaktır.

\section{KAYNAKÇA}

Axelsen, M. (2009). The Power of Leisure: I Was an Anoexic; I'm Now a Healthy Triathlet, Lesiure Sciences, 31: 330-346.

Baud-Bovy ve Lawson, F. (2002). Tourism and Recreation Randbook of Planning and Design. İngiltere: Architectural Press.

Birleşmiş Milletler (2020). Facts and Figures: Ending Violence against Women, Various Forms of Violence. https:// www.unwomen.org/en/what-we-do/ending-violence-against-women/facts-and-figures, (Erişim tarihi: 18.03.2020).

Brás, M. (2015). Tourism and Crime - Why Tourists Become Victims, Security \& Tourism: Local Policies and Practices Conference, 25 Haziran 2015. Fransa: Paris.

Brosnan, S. (2019). The Impact of Sports Participation on Crime in England between 2012 and 2015, Sport in Society, 1-12. DOI: $10.1080 / 17430437.2019 .1631805$.

Brunt, P. ve Hambly, Z. (1999) Tourism and Crime: A Research Agenda, Crime Prevention and Community Safety, 1 (2): 25-36.

Butchart, A, Brown, D, Wilson, A. ve Mikton, C. (2008). Preventing Violence and Reducing Its Impact: How Development Agencies Can Help, World Health Organization, https://apps.who.int/iris/bitstream/hand- le/10665/43876/9789241596589_eng.pdf, (Erişim tarihi: 18.03.2020).

Carnegie Council (2001). Introduction: Rights and the Struggle for Health. https://www.carnegiecouncil.org/publications/archive/dialogue/2_06/articles/359, (Erişim tarihi: 18.03.2020).

California Department of Youth Authority (CDYA). (2002). Annual Report 2001 Program Description and Statistical Summary. CA: CDYA.

Cameron, M. ve MacDougall, C. (2000). Crime Prevention Through Sport And Physical Activity, Australian Institute of Criminology. https://aic.gov.au/publications/tandi/ tandi165, (Erişim tarihi: 18.03.2020).

Caruso, R. (2011). Crime and Sport Participation: Evidence from Italian Regions over the Period 1997-2003, The Journal of Socio-Economics, 40 (5): 455-463.

DSÖ (2012). Violence and Injury Prevention, https://www.who. int/violence_injury_prevention/publications/violencelexplaining/en/, (Erişim tarihi: 14.04.2012).

Dünya Bankası (1999). Poverty Reduction and the World Bank: Progress in Fiscal 1999. World Bank Publications. http://documents.worldbank.org/curated/ en/465181468164057191/pdf/31105.pdf, (Erişim tarihi: 18.03.2020)

Iwasaki, Y. (2007). Leisure and Quality of Life in an International and Multicultural Context: What are Major Pathways Linking Leisure to Quality of Life, Social Indicators Research, 82: 233-264.

Jenkins, J. ve Pirgam, J. (2006). Outdoor Recreation. İçinde Rojek, C., Shaw, S. and Veal, A. (Editörler), Handbook of Leisure Studies. UK: Palgrave Macmillan.

Jones, C., Barclay, E. ve Mawby, R.I. (2012). The Problem Of Pleasure: Leisure, Tourism and Crime. Londra: Routledge.

Karaküçük, S. (1997). Rekreasyon (Boş Zamanları Değerlendirme) Kavram, Kapsam ve Bir Araştırma (İkinci baskı). Ankara: Seren Ofset.

Kolata, G. (2002). TV Linked to Aggression among Teens, Youth. The Sacramento Bee. March 29, A7.

Meeras, L. (2010). Leisure and Recreation. Parnu: University of Tartu.

Mendel, R. (2000). What Works in the Prevention of Youth Crime. CYC Online. http://www.cyc-net.org/cyc-online/ cycol-0500-mendler.html, (Erişim tarihi: 18.03.2020).

Patry, D.A., Blanchard, C.M. ve Mask, L. (2007). Measuring University Students' Regulatory Leisure Coping Styles: Planned Breathes or Avoidance?, Leisure Sciences, 29: 247-265.

Schwarzenegger, Chrisman, M. ve Coleman, R. A. (2005). The Health and Social Benefits of Recreation. An Element of the California Outdoor Recreation Planning Program. California: State of California Resources Agency. www.parks.ca.gov/pages/795/files/benefits\%20final\%200nline\%20v6-1-05.pdf, (Erişim tarihi: 18.03.2020).

Şener, A., Terzioğlu, R. G. ve Karabulut, E. (2007). Life Satisfaction And Leisure Activities during Men's Retirement: a Turkish Sample, Aging and Mental Health, 11 (1): 30-36. 
Torkildsen, G. (1999). Leisure and Recreation Management. 4. Baskı. Londra: E \& FN Spon.

Trust for Public Land (TPL). (1994). Healing America's Cities: Why We Must Invest in Urban Parks. San Francisco, CA: The Trust for Public Lands National Office.

Tütüncü, Ö. (2008). Rekreasyon Yönetimine Yönelik Üniversite Düzeyinde Bir Müfredat Geliştirme Önerisi, Anatolia Turizm Araştırmaları Dergisi, 19 (1): 93-103.

Tütüncü, Ö, Aydın, İ, Küçükusta, D, Avc1, N ve Taş, İ. (2011). Üniversite Öğrencilerinin Rekreasyon Faaliyetlerine Katılımını Etkileyen Unsurların Analizi, Hacettepe Spor Bilimleri Dergisi, 22 (2): 69-83.

Tütüncü, Ö. ve Kuşluvan Z. (1997). Çevre Sorunlarının Doğada Rekreasyon Faaliyetlerine Duyulan Gereksinimi Artırıcı Etkisi, Anatolia: Turizm Araştırmaları Dergisi, 8 (1): 9-11.

Quackenbush, C. (2019). The World's Top 26 Billionaires Now own as much as the Poorest 3.8 Billion, Says Oxfam. Time. https://time.com/5508393/global-wealth-inequality-widens-oxfam/, (Erişim tarihi: 18.03.2020).
UNODC (2020). Intentional Homicide Victims. United Nations Office on Drugs and Crime. https://dataunodc. un.org/crime/intentional-homicide-victims, (Erişim tarihi: 18.03.2020).

Usal, A. (1981). Çağdaş Bunalım/Turizm, Ege Üniversitesi İşletme Fakültesi Dergisi, 1 (1-2): 13-19.

Wiktionary (2020). The Free Dictionary. https://en.wiktionary. org/wiki/licere, )Erişim tarihi: 18.03.2020).

Williamson, D. (2000). Study: Crime, Lack of PE, Recreation Programs Lead U.S. Adolescents to Couch- Potato Lifestyles. UNC News Services. http://www.unc.edu/ news/archives/jun00/popkin6060500.htm, (Erişim tarihi: 18.03.2020)

Williams, D.J. ve Gordon, J. W. (2006). Leisure, Deviant Leisure, and Crime: Caution: Objects may be Closer than they Appear, Leisure/Loisir, 30 (1): 193-218.

Özkan TüTÜNCÜ, Prof. Dr., Dokuz Eylül Üniversitesi, Spor Bilimleri Fakültesi, Rekreasyon Bölümü, 35330 İzmir.

E-posta: ozkan.tutuncu@deu.edu.tr

ORCID: 0000-0002-2482-0893 